\title{
Erratum to: RPAS and GIS for landfill analysis
}

\author{
Ignas Daugela ${ }^{1, \mathrm{a}}$, Jurate Suziedelyte Visockiene ${ }^{2}$, and Vladislovas Ceslovas Aksamitauskas ${ }^{3}$ \\ ${ }^{1,2,3}$ Department of Geodesy and Cadastre, Vilnius Gediminas Technical University, Sauletekio av. 11, Vilnius, Lithuania
}

Original article: E3S Web of Conferences 44, 00025 (2018), https://doi.org/10.1051/e3sconf/20184400025

\section{The citation and text in the sentences of the 1.1 chapter should be corrected:}

The line 39: Such a classification for civilian UAVs is taken from the military (Fig. 2) [3, 4].

The line 44: Fig. 2. Examples of fixed-wing unmanned aerial systems (UAS) platforms for trace gas monitoring [5]. The line 47: The aircraft's flight height, duration, load lift capacity is influenced by its size. These aircrafts can be considered as the category of MINI UAVs (MUAV) $[4, \mathbf{5}, \mathbf{6}]$.

The line 61: For each pixel of each photo they usually capture 5-7 spectral bands, of which 1-2 bands captures part of the NIR wave spectrum, the red and green spectra, and spectrum corresponding color red is divided into several parts, since in case of plant investigation, the so-called Red Edge range is extremely informative (helpful) [7].

The line 67: In this case, the information is captured by a slightly different principle ("Push-broom") - not by capturing a rectangular picture, but one line of pixels, that represent one band spectrum instead and the entire sensor travels with the aircraft in the desired direction, simultaneously covering same pixels with all different possible bands $[4,7,9]$. The line 68: There are also attempts to produce small lightweight camera-type spectrometers [8, 9] (Fig. 3).

The line 78: The suitability of these systems for further research, industrial or everyday life application depends on that $[8,9]$.

The line 82: The more complex main sensor used, the more important is the overall calibration of the system [9, 10]. The line 86: From relevant (just captured) images, orthophotographic images are created for mapping the area with precise contours, topographic material is updated with generated height information (DSM - Digital Surface Model, Fig. 4).

The line 88: Fig.3. Airborne Imaging Sensor products [http://www.itres.com/].

The line 95: Collected material is processed by specialized software, capable of performing classical photogrammetric and previously mentioned SfM photo processing and simulation (modeling) works in GIS [6].

\section{The citation and text in the sentences of the 1.2 chapter should be corrected:}

The line 104: During review of the literature noted CALMIM software, that calculates the annual methane emission estimate of landfills for individual sites, based on the key processes that determine the emissions $[\mathbf{1 1}, \mathbf{1 2}, \mathbf{1 3}]$. The line 151: Published literature on this topic over decade points out that due to specific local characteristics, the previous reliance on first-class kinetic models for the formation of methane of a landfill as a basis for predicting emissions is not precise, it is necessary to replace better, more scientifically based methodology for the following reasons [11-15]:

\section{The citation and text in the sentences of the 2.1 chapter should be corrected:}

The line 186: The shooting of pictures was done in May 2015 and May 2016, using a Trimble UX5 UAV with a Sony NEX-5R digital camera, which was updated before second time. An orthophoto was generated from the photos using the Trimble Business Center Photogrammetry Module (TBC) software, with an average pixel size (equivalent on the ground - GSD) of $14.4 \mathrm{~cm}$ (2015), $3.5 \mathrm{~cm}$ (2016) and colored with corresponding RGB value (Fig. 5).

The line 202: By comparing visually (Fig. 4), it is evident that the vegetation in the northern part of the territory is livelier, and the slopes of the reservoirs of sediment located in the western part of the territory are changing.

\footnotetext{
a Corresponding author: ignas.daugela@vgtu.lt
} 
The line 213: There are various types of sensors that can be mounted on a UAV to detect greenhouse gas and VOC traces in the lower part of the atmosphere. The most commonly used methods are electrochemical, photoionization, infrared (IR) laser absorption, semiconductor and catalytic detection. Although each method is fundamentally different, all types of sensors must be able to detect levels of ambient atmospheric concentration and also have a dynamic range that covers the range of gas that is expected to be [5].

\section{The citation and text in the sentences of the 2.2 chapter should be corrected:}

The line 215: 2.2. Territory modeling with CALMIM

The line 255, 257: Spokas and Bogner (2011) in the literature are reviewing such geo-modeling (by geographic coordinates/ location) and claiming that location differences of less than $5^{\circ}$ are often not worthy of consideration [13]. The line 267: French Environment Agency (ADEME) on the strength of research of K. Spokas and others, has set guidelines, such as: methane emissions are reduced by $90 \%$ for the area covered by the geomembrane and an active gas collection or incineration system [11].

The line 271: Already in 1997 published article, it was written that after testing the properties of the geomembrane (like isolation of the landfill filtrate, stopping of methane formation, static and dynamic pressure) resistance after approximately 8 years of use has not diminished [16].

\section{Corrected list of references:}

Line from 308:

1. E. Mitka, S. G. Mouroutsos. Class. of Dron. American Journal of Engineering Research (AJER), 6 (7), $2320-0936$ (2017)

2. I. Colomina, P. Molina. Unm. aer. syst. for photogr. and rem. Sens.: A rev. ISPRS Journ. of Photogr. and Rem. Sens., 92, 79-97 (2014)

3. A, C, Watts, V. G. Ambrosia, E. A. Hinkley. Unm. aircr. syst. in rem. sens. and scient. res.: Classific. and consid. of use. Rem. Sens., 4(6), 1671-1692 (2012)

4. S. G. Gupta, M. M. Ghonge, P. M. Jawandhiya. Rev. of Unm. Aircr. Syst. (UAS). Int. J. of Adv. Res. in Comp. Eng. \& techn. (IJARCET), 2 (4), $2278-1323$ (2013)

5. T. J. Schuyler, M. I. Guzman. Unm. Aer. Syst. for Monit. Tr. Trop. Gas. Atm., 8, 206, doi:10.3390/atmos8100206 (2017)

6. H. Eisenbeiss. A Mini Unm. Aer. Veh. (UAV): Syst. overv. and image acq. ISPRS Arch., XXXVI-5/W1, 1-7 (2004)

7. P. Baecka, J. Blommaerta, S. Delalieuxa, B. Delauréa, S. Livensa, D. Nuytsa, A. Simaa, G. Jacqueminb, J. P. Goffartb. High res. Veg. mapp. with a novel compact hypersp. cam. syst. The 13th Int. Conf. on Prec. Agric. (2016)T.

8. Skauli, H. E. Torkildsen, S. Nicolas, T. Opsahl, T. Haavardsholm, I. Kåsen, A. Rognmo. Comp. cam. for multisp. and conv. Imag. based on patt. filt. Appl. Opt., 53(13), C64-C71 (2014)

9. S. Livens, K. Pauly, P. Baeck, J. Blommaert, D. Nuyts, J. Zender, B. Delauré. A Spatio-Spectral Cam. for high Res. Hypersp. Im. Int. Arch. of the Photogr., Rem. Sens. \& Spat. Inf. Sc., 42 (2017)

10. H. Aasen, A. Burkart, A. Bolten, G. Bareth. Gen. 3D hypersp. inf. with lightw. UAV snapsh. cam. for veg. monit.: From cam. Calibr. to qual. assur. ISPRS J. of Photogr. and Rem. Sens., 108, 245-259 (2015)

11. K. A. Spokas, J. Bogner, J. P. Chanton, M. Morcet, C. Aran, C. Graff, Y. Moreau-Le Golvan, I. Hebe. Meth. mass bal. at three landfill sites: What is the eff. of capture by gas coll. syst.? Waste man., 26(5), 516-525 (2006)

12. K. A. Spokas, J. E. Bogner. Lim. and Dyn. of Meth. Ox. in Landfill Cov. S. Was. Manag., doi:10.1016/j.wasman.2009.12.018 (2010)

13. J. E. Bogner, K. A. Spokas, J. P. Chanton. Seas. Gre. Gas Em. (M., Car., Dio., Nit. Ox.) from Eng. Landfills: D., Interm., and Fin. Cal. Cov. S. Tech. rep.: Was. Manag., JEQ, 40, 1010-1020, doi:10.2134/jeq2010.0407 (2011)

14. G. Börjesson, I. Sundh, A. Tunlid, A. Frostegard, B. H. Svensson. Meth. Oxid. in landfill cover soils as rev. by pot. ox. meas. and phosph. fatty acid anal. Soil Biol. Bioch. J. of Env. Qual., 40, 30:1423-1433 (2011)

15. I. Sundh, G, Börjesson, A. Tunlid. Meth. Oxid. and phosph. fatty acid comp. in a podz. soil prof. J. of Soil Biol. \& Bioch. 32, 1025-1028, (2000)

16. A. W. Eithe, G. R. Koerner. Assessm. of HDPE geom. perf. in a munic. waste landfill double liner syst. after eight years of serv. Geot. and Geomembr., 15(4-6), 277-287 (1997) 